\title{
BMJ Open Effects of perioperative briefing and debriefing on patient safety: a prospective intervention study
}

\author{
Katharina Brigitte Margarethe Siew Lan Leong, ${ }^{1}$ Mirelle Hanskamp-Sebregts, ${ }^{2}$ \\ Raymond A van der Wal, ${ }^{1}$ Andre P Wolff ${ }^{3}$
}

To cite: Leong KBMSL, Hanskamp-Sebregts M, van der Wal RA, et al. Effects of perioperative briefing and debriefing on patient safety: a prospective intervention study. BMJ Open 2017;7:e018367. doi:10.1136/ bmjopen-2017-018367

- Prepublication history and additional material for this paper are available online. To view these files, please visit the journal (http://dx.doi.org/10. 1136/bmjopen-2017-018367)

Received 26 June 2017 Revised 1 September 2017 Accepted 5 October 2017

CrossMark

1Department of Anaesthesiology, Pain and Palliative Medicine, Radboud University Medical Center, Nijmegen, The

Netherlands

${ }^{2}$ Institute of Quality Assurance and Patient Safety, Radboud University Medical Center,

Nijmegen, The Netherlands

${ }^{3}$ Department of Anaesthesiology, Pain Center, University of Groningen, University Medical Center Groningen, Groningen, The Netherlands

Correspondence to Drs. Mirelle HanskampSebregts;

mirelle.hanskamp-sebregts@ radboudumc.nl

\section{ABSTRACT}

Objectives This study was carried out to improve patient safety in the operating theatre by the introduction of perioperative briefing and debriefing, which focused on an optimal collaboration between surgical team members.

Design A prospective intervention study with one pretest and two post-test measurements: 1 month before and 4 months and 2.5 years after the implementation of perioperative briefing and debriefing, respectively.

Setting Operating theatres of a tertiary care hospital with 875 beds in the Netherlands.

Participants All members of five surgical teams participated in the perioperative briefing and debriefing. Intervention The implementation of perioperative briefing and debriefing from July 2012 to January 2014.

Primary and secondary outcomes The primary outcome was changes in the team climate, measured by the Team Climate Inventory. Secondary outcomes were the experiences of surgical teams with perioperative briefing and debriefing, measured with a structured questionnaire, and the duration of the briefings, measured by an independent observer.

Results Two and a half years after the introduction of perioperative briefing and debriefing, the team climate increased statistically significant $(p \leq 0.05)$. Members of the five surgical teams strongly agreed with the positive influence of perioperative briefing and debriefing on clear agreements and reminding one another of the agreements of the day. They perceived a higher efficiency of the surgical programme with more operations starting on time and less unexpectedly long operation time. The perioperative briefing took less than 4 min to conduct. Conclusions Perioperative briefing and debriefing improved the team climate of surgical teams and the efficiency of their work within the operating theatre with acceptable duration per briefing. Surgical teams with alternating team compositions have the most benefit of briefing and debriefing.

\section{INTRODUCTION}

An operating theatre is a hospital department where highly complex care is provided. Several factors contribute to a higher risk of mistakes than in other hospital departments: different team compositions from day to day, complex surgery, high-risk medication, time pressure, high patient turnover and need

\section{Strengths and limitations of this study}

- We measured the long-term effect of the perioperative briefings and debriefings on the team climate (2.5 years after the implementation).

- We evaluated the perioperative briefing and debriefing before roll-out of this intervention to other surgical teams and tested the evaluation questionnaire before using it to guarantee a successful implementation and measurement of the experiences.

- Despite no other changes made during the implementation of perioperative briefing and debriefing, we did not randomise to deal with possible unknown confounders that also could have had an influence on the association of perioperative briefing and debriefing and the team climate within surgical teams.

- The response rate on the Team Climate Inventory and evaluation questionnaire was low due to the high number of people who could have filled out the questionnaire.

- We did not have objective observations to confirm the efficiency of perioperative briefing and debriefing, nor did we measure patient safety outcomes such as adverse events related to surgery to confirm the effect of the improved team climate on patient safety.

for rapid intervention in the case of emergency surgery. High incidence of adverse events $(2.9 \%-3.7 \%$ of hospitalisations) leads to high costs, patient harm and loss of trust in healthcare. ${ }^{1}$ In Dutch hospitals, $7.1 \%$ of all admitted patients experience an adverse event, of which $54.8 \%$ is related to surgery and $24.3 \%$ is related to medication. ${ }^{2}$

Technical and medical problems are not the main contributing factors to adverse events, but rather, problems in communication or insufficient team work are leading to errors in healthcare. ${ }^{34}$ Therefore, check lists (eg, time-out and sign-out check lists) were introduced to operating theatres worldwide to prevent wrong-site surgery (time out), to document procedures, to count used 
materials and verify postprocedure orders (sign out). ${ }^{5}$ The use of these check lists has led to a $47 \%$ reduction in mortality and $36 \%$ reduction in morbidity, ${ }^{6}$ and mortality rates fell $62 \%$ when the check lists were used for emergency procedures. ${ }^{7}$ However, the effectiveness of safety check lists is debatable: to what extent the check lists improve the clinical outcomes ${ }^{8}$ depends on the implementation and usage of the check lists and safety attitudes of the team members. ${ }^{9} 10$ Low compliance with safety check lists is reported. ${ }^{11}{ }^{12}$ Despite a successful implementation of check lists in our hospital, ${ }^{13}$ a hierarchical system remains in the operating room: we perceived that, if not everyone is familiar with each other's name and function, then communication and speaking up about problems is hampered. This situation of miscommunication is a potential threat to patient safety because problems can easily go unnoticed to the whole team. Therefore, we introduced perioperative briefings and debriefings in our hospital to attempt to break through this hierarchy and create a working environment where information is shared readily and barriers to speaking up are lowered. The perioperative briefing and debriefing are additional to the time-out and sign-out procedures to improve functioning of surgical teams. Time out and sign out have become universal whole-surgery-team efforts (respectively immediately before anaesthesia induction and after surgery) to reduce the risk of adverse events. ${ }^{5}{ }^{14}$ Our briefings and debriefings, however, are done before and after the end of the day's list in the operating room in a standardised way, targeting towards work efficiency, cooperation and team functioning. One of the most important characteristics of a well-functioning team, especially when comprising professionals from diverse backgrounds such as surgical teams, is their team climate. Research has shown that team climate is positively related to providing high-quality care ${ }^{1516} \mathrm{~A}$ briefing-debriefing process in the operating theatre may promote patient safety by adding continuous improvement through reflective learning and immediate feedback ${ }^{17}$ and an improved efficiency in running an ideal operating list. ${ }^{18}$ Working with perioperative briefings and debriefings can also have a positive effect on collaboration and communication, which may be strengthened in combination with team training. ${ }^{19}$ However, we focus in this study on introducing perioperative briefings and debriefings. We hypothesised that improvement in team climate of surgical teams would contribute to improved patient safety in the operating theatre. Our study aim is to evaluate changes in the team climate of surgical teams, associated with the introduction of the perioperative briefings and debriefing in the operating theatres, and the experiences of the members of the surgical teams with the perioperative briefing and debriefing regarding work efficiency and cooperation.

\section{METHODS}

\section{Study design, population and measurements}

Our study was a prospective before and after intervention study with the perioperative briefing and debriefing as the intervention in the operating theatre (for definitions and aims, see table 1). We measured the before and after change in team climate of five surgical teams of a tertiary care hospital with 875 beds in the Netherlands. The five surgical teams representing seven surgical specialties were: general surgery; orthopaedic surgery; gynaecological surgery; neurosurgery/plastic surgery; ear-nosethroat surgery/mouth-jaw-facial surgery. Per day, the surgical team is mainly a fixed team; however, assistance of an external surgical assistant or anaesthetic nurse is common, caused by shortage of personnel. Also during the year, there is a considerable change in personnel especially of the number of surgeons, anaesthesiologists and nurses in training due to their education.

We measured the team climate of surgical teams using the Team Climate Inventory (TCI).$^{20} 21$ The TCI is a reliable and valid questionnaire, using a 5-point Likert scale (1-5), to measure team climate as an outcome measure of quality improvement strategies. The TCI evaluates four climate factors: 'participative safety', 'support for innovation', 'vision' and 'task orientation'. These factors are essential for successfully implementing innovations such as the perioperative briefing and debriefing. We also evaluated the experiences of the members of the surgical teams by using a standardised questionnaire, which was

Table 1 The definitions and aims of perioperative briefing and debriefing

\begin{tabular}{|c|c|c|}
\hline Intervention & Description & $\begin{array}{l}\text { Aims related to work efficiency } \\
\text { and team functioning }\end{array}$ \\
\hline Perioperative briefing & $\begin{array}{l}\text { Briefing is carried out before the first patient arrives in the } \\
\text { operating theatre. All the members of the surgical team share } \\
\text { essential information for that day: introduction round, tasks of } \\
\text { the team members and expected technical or logistical issues } \\
\text { that require extra attention. }\end{array}$ & $\begin{array}{l}\text { To stimulate mutual support for the } \\
\text { tasks that day. } \\
\text { To immediately resolve the } \\
\text { expected technical or logistical } \\
\text { problems. }\end{array}$ \\
\hline
\end{tabular}


specifically designed to measure both the perioperative briefing and debriefing separately. A 5-point Likert response scale was used ranging from 1 being 'disagree strongly' to 5 representing 'agree strongly' with statements about work efficiency and cooperation. Additionally, participants could report perceived strengths and limitations of the briefing and debriefing. Before using this questionnaire, a small pilot study was carried out to test the feasibility and face validity and did not result in any updates. Both questionnaires were distributed by email to all team members of the surgical teams (surgeons, surgeon residents, fellow surgeons, anaesthesiologists, anaesthesiology residents, surgical assistants and anaesthetic nurses) who worked at least four times during the implementation period of the perioperative briefing and debriefing. We considered the cut-off point of four times as an acceptable exposure of the intervention. The TCI was distributed 1 month before and (together with the evaluation questionnaire) 4 months after the implementation of the perioperative briefing and debriefing. Additionally, we sent both questionnaires 2.5 years later to measure long-term effects of the perioperative briefing and debriefing. Finally, an independent observer (medical student) measured the time in minutes of the perioperative briefings to evaluate their impact on the operating room start times.

\section{Implementation of the perioperative briefing and debriefing}

The perioperative briefing and debriefing were stepwedge implemented in the period from July 2012 to January 2014. A dedicated anaesthesiologist carried out the implementation during 4 months per surgical team by training on the job. A 'briefing card' with topics about the personnel, operating programme and patients was used to structure and standardise the perioperative briefing and debriefing (figure 1). Before rolling out the perioperative briefing and debriefing, we evaluated this intervention after the implementation within the first surgical team and made small changes on the briefing card. After the implementation, the perioperative briefing and debriefing are led by the surgeon or the scrub nurse.

\section{Data analysis}

After the data collection, data were checked on a regular basis to identify out-of-range answers, inconsistent responses and missing data. We calculated the response rates of the TCI and evaluation questionnaire before and after the intervention. A linear mixed model was used to measure changes in the team climate scores and adjusted for clustering of surgical teams. If this model provided no fit of the data, we omitted the random effect for teams. A $p$ value of $\leq 0.05$ was regarded as statistically significant. The experiences of surgical team members were assessed by using descriptive statistics. Respondents were regarded as having a 'positive' experience to the perioperative briefing and debriefing if they returned an item score of 7.5 or greater on a scale of $1-10$ or $\geq 4$ on the 5-point Likert scale. We tabulated the perceived strengths and limitations of perioperative briefing and debriefing and counted the most frequently mentioned strengths and limitations. ${ }^{22}$ Statistical software IBM SPSS V.22 was used for all statistical analyses and data processing.

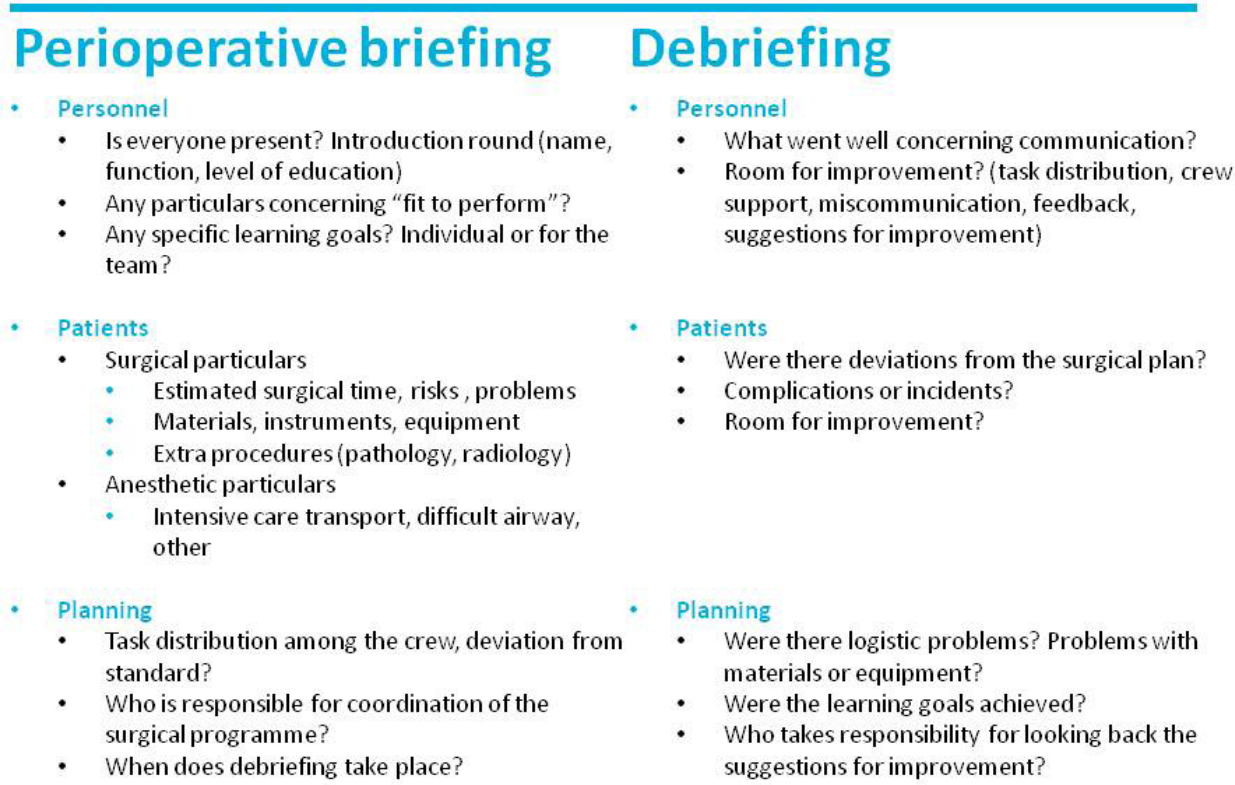



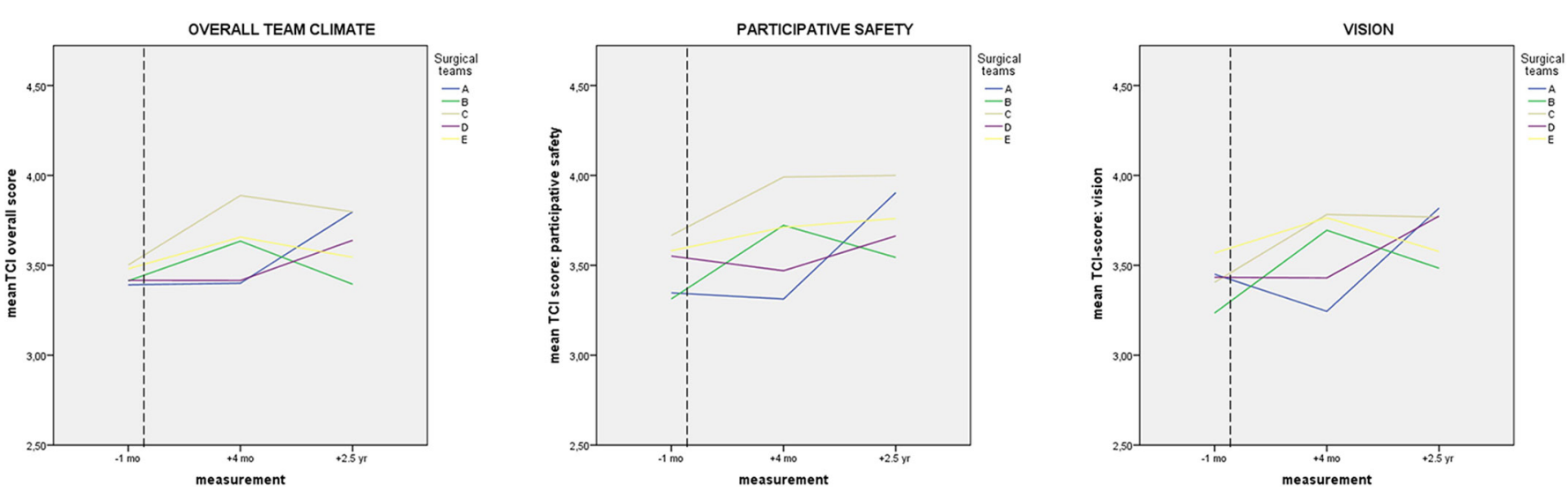

Figure 2 Mean TCl scores: overall, dimensions 'participative safety' and 'vision' at 1 month before and 4 months and 2.5 years after the implementation of the perioperative briefing and debriefing. TCI, Team Climate Inventory.

\section{RESULTS}

The TCI response rate before and after the implementation was $27.0 \%(184 / 681)$ and $16.4 \%(113 / 687)$, respectively. The response rate of the evaluation questionnaire was $17.7 \%(123 / 695)$. In 2016, the response on both questionnaires was $28.6 \%(107 / 374)$.

\section{Team climate}

The overall TCI scores 2.5 years after the implementation of the perioperative briefing and debriefing had a statistically significant increase on a scale of $1-5, \mathrm{p}=0.05$ $(0.18 ; 95 \% \mathrm{CI}-0.01$ to 0.38$)$, in particular the dimensions 'participative safety' and 'vision', $\mathrm{p}=0.02 \quad(0.28$; $95 \%$ CI 0.06 to -0.50$)$ and $\mathrm{p}=0.04(0.24 ; 95 \%$ CI 0.01 to 0.46 ), respectively (see figure 2 ). Only the subdimension 'clarity' of the dimension 'vision' increased after 4 months $(0.24 ; 95 \%$ CI 0 to $0.48 ; p=0.05)$. All the results of the TCI measurements are represented in online supplementary appendix 1 .

\section{Experiences of members of surgical teams}

The team members of the five surgical teams gave a mean score of 6.8 (SD 1.5) for efficiency in 2014 as a result of the perioperative briefing and debriefing and 7.5 (SD 1.4) for cooperation on a scale of 1-10. In 2016, the mean score for efficiency was 7.2 (SD 1.4) and for cooperation 7.6 (SD 1.3). The median score for efficiency changed from 7 in 2014 to 8 in 2016. The median score for cooperation was 8 in 2014 and 2016. In 2016, the percentage (strong) agreement increased on 7 of the 13 items comparing with the percentage (strongly) agreement compared with 2014 (see figure 3). Overall results showed

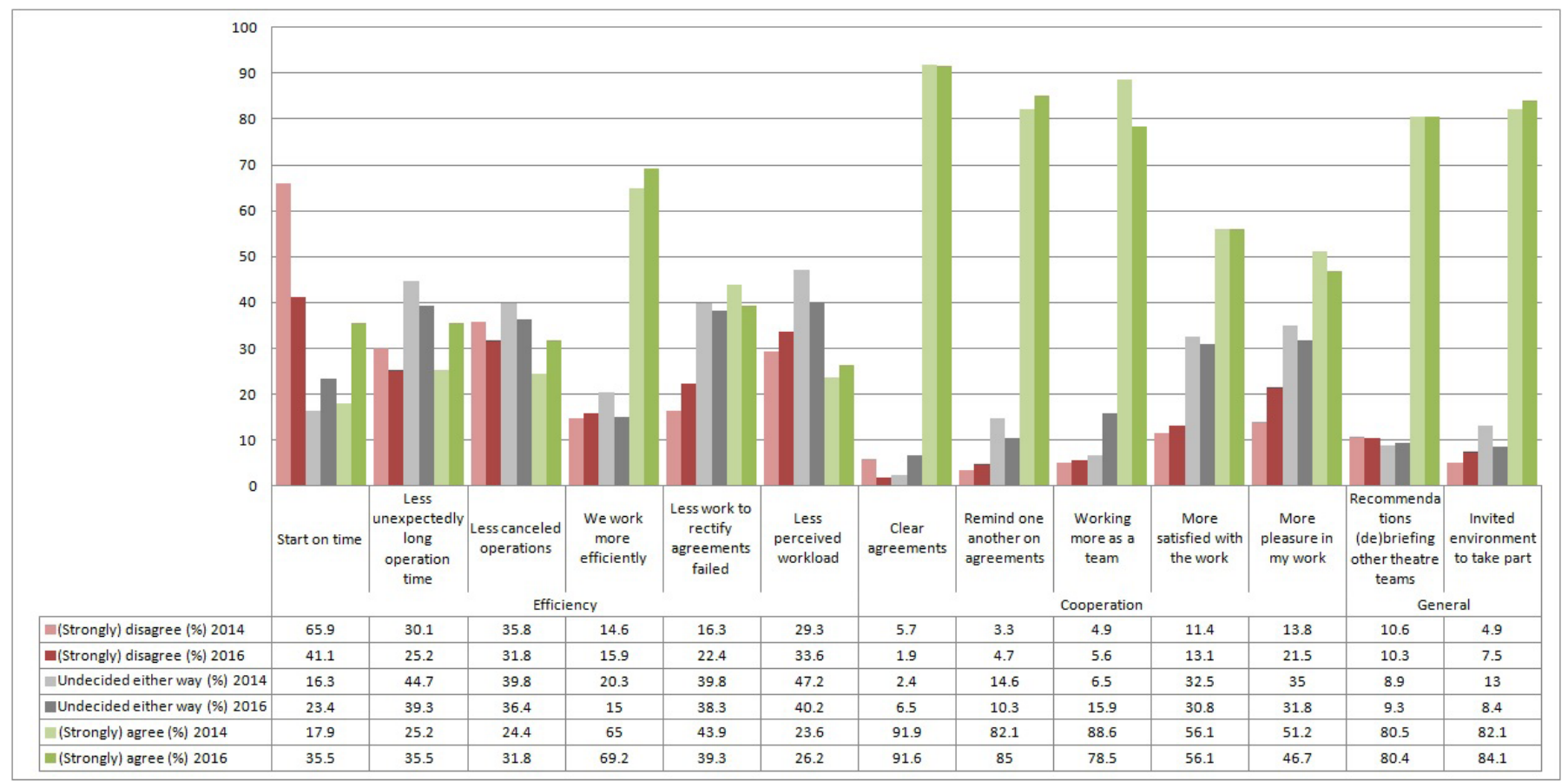

Figure 3 Experiences of the members of the five surgical teams with perioperative briefing and debriefing in $2014(\mathrm{n}=123)$ and $2016(n=107)$. 
that perioperative briefing and debriefing were popular among team members. Of the team members, $92 \%$ indicated that the perioperative briefing and debriefing made the agreements of the day clear to them, $85 \%$ indicated that they reminded one another of the agreements and $84 \%$ experienced an inviting environment to take part in the perioperative briefing and debriefing. Also, $80 \%$ of the team members recommended the introduction of perioperative briefing and debriefing to other theatre teams. However, the items 'start on time' (35.5\%), 'less unexpectedly long operation time' $(35.5 \%)$ and 'less perceived workload' (26.2\%) had the lowest percentage (strong) agreement, although these items improved compared with 2014 and the percentage disagreement decreased slightly for the items 'start on time' (24.8\%) and 'less unexpectedly long operation time' $(4.9 \%)$. The percentage (strong) agreement of the items 'working more as a team' and 'more pleasure in my work' decreased $10.1 \%$ and $4.5 \%$, respectively, in 2016 compared with 2014. The percentage (strong) disagreement of the item 'more pleasure in my work' increased $7.7 \%$ in 2016.

Participants mentioned that the briefing and debriefing both improved their feeling of working as a team and team members knowing each other better and that it led to more clear communication. However, the debriefing was evaluated less positively because participants perceived that the debriefing is not structurally carried out, often with an incomplete team and hastily performed. Some members felt that debriefing was less useful than briefing because they had the idea that little is done with the discussed problems and learning points.

The time to conduct a perioperative briefing was $<4 \mathrm{~min}$ $(\mathrm{n}=121$, variation $1-10 \mathrm{~min})$ and varies little with the pretest in July 2012 (mean $3.55 \mathrm{~min}$ ) and the post-test in January 2014 (mean 3.29 min).

\section{DISCUSSION}

\section{General findings}

Our results show that the introduction of perioperative briefing and debriefing positively influenced the team climate of five surgical teams, especially on the dimensions 'participative safety' and 'vision'. Team members felt safer about sharing their observations and opinions with the rest of the team. Also, working as a team to reach a learning objective (higher goal) was appreciated as a positive stimulus; however, this appreciation decreased $10 \%$ 2.5 years after the implementation. We found that the team members perceived that especially the debriefing was insufficient. Debriefing is an essential part of the intervention because, in the debriefings, problems and interventions for improvement are discussed. Renewed attention for the importance of the performance of the debriefing might lead to better teamwork.

An important issue that can make staff reluctant to engage in briefings and debriefings is the assumption that they consume much time and delay surgical programmes. Our observations showed that the briefing is carried out in less than 4 min and leads to a perceived higher efficiency of the surgical programme with more surgeries starting on time and less cancellations. Other studies confirm that a preoperative briefing can be carried out in less than $2 \mathrm{~min}$ and objectively does not delay surgery starting times. ${ }^{23}$

Our results correspond with previous studies evaluating the effect of perioperative briefings and debriefings: Papaspyros $e \mathrm{al}^{17}$ reported the fact that both interventions help with communication between all members of surgical teams and that people are willing to speak up when they are not happy with something. Ahmed et al ${ }^{18}$ have shown that the introduction of a brief-debrief system, as part of a module-based theatre improvement programme, ${ }^{24}$ leads to improvements in efficiency measures such as start/overrun times. Bartz-Kurycki et $a l^{25}$ found also that the fact that debriefings in the operating room were not fully executed related to a lack of institutional awareness of its potential benefits. Despite this, debriefing is emphasised as a powerful tool to identify lessons learnt shortly after a procedure with the aim to improve future performance on an individual and team level. ${ }^{2627}$

\section{Strengths and limitations}

To our knowledge, no other changes or implementations were made during the intervention period that could have interfered with the team climate in the operating room. Also, the composition of the surgical teams was highly variable. Therefore, the improvement in team climate was not a result of the fact that team members had the opportunity to work together frequently during the intervention period. The results mainly reflect the effect of the perioperative briefings and debriefings on the team climate. We also measured the team climate and experiences of the members of the surgical teams 2.5 years after the implementation of perioperative briefing and debriefing within the last surgical team. Therefore, we can demonstrate longterm effects of perioperative briefing and debriefing. We evaluated the perioperative briefing and debriefing after implementation in one surgical team before rolling out this intervention to other teams and tested the evaluation questionnaire before using it to guarantee a successful implementation and measurement of the experiences.

Our study had some limitations. We used a beforeafter study design without a control group. We did not randomise to deal with possible unknown confounders that also could have had an influence on the association of perioperative briefing and debriefing and the team climate within surgical teams. The response rate in our study was low: $17.7 \%-28.6 \%$. However, response rates below $20 \%$ are not uncommon. ${ }^{28}{ }^{29}$ We included all the team members who worked in the operating room at least four times during the implementation period. This decision led to a high number of people who could have filled out the questionnaire. However, this potential number of participants may have been falsely high, leading to a low response rate. This low response rate and the fact that probably only the positive-minded team members responded create the risk that our results do not represent all the staff working in 
the operating room. We did not have objective observations to confirm the efficiency of perioperative briefing and debriefing, for example, drop-out of operations at the end of the day. Neither did we measure patient safety outcomes, such as adverse events related to the surgery, to confirm the effect of the improved team climate on patient safety. The Safety Attitude Questionnaire is a proper tool to measure and assess patient safety culture in an operating theatre. ${ }^{30}$ We preferred the TCI in our study because the TCI can both be used as an outcome measure of the quality-improvement intervention and the perioperative briefing and debriefing and it can predict the success or failure of this intervention. ${ }^{20}$ The TCI also identifies team climate areas that could be improved and lead more directly to better healthcare and healthcare outcomes than in case of changing the patient safety attitudes of members of surgical teams. More studies with a randomised clinical trial design in hospitals where the composition of surgical teams varies daily are required to show that perioperative briefing and debriefing actually improve patient safety by affecting teamwork of surgical teams.

\section{CONCLUSIONS}

We hypothesised that the briefing and debriefing are probably most effective in tertiary care hospitals where teams differ every day. Smaller community hospitals generally have less alternating team compositions and may therefore benefit less from the implementation.

Our results show significant improvement of the team climate after implementation of the perioperative briefing and debriefing. The time investment for these interventions appears to be acceptable, lasting less than $4 \mathrm{~min}$. We recommend hospitals working with alternating surgical team compositions to implement the briefing and debriefing. When implementing the intervention, registration of actual starting times and cancellation of surgeries before and after the implementation should provide even more evidence for the efficiency. Perioperative briefings and debriefing lead to improved efficiency and, most importantly, improved team climate of surgical teams and have therefore positive influence on patient safety in the operating theatre.

Acknowledgements We thank Maartje Frijlink (anaesthesiologist) for her contribution to the first version of this manuscript.

Contributors KBMSLL and MH-S led the writing of the first draft and revised this manuscript. RAvdW and APW developed and implemented the perioperative briefing and debriefing and contributed to critical revision of the manuscript. MH-S and RAvdW collected the data. KBMSLL and MH-S analysed and interpreted the data. All authors approved the version of the manuscript for publication.

Competing interests None declared.

Ethics approval Research Ethics Committee of the Radboud University Medical Center.

Provenance and peer review Not commissioned; externally peer reviewed.

Data sharing statement On request available to the corresponding author.

Open Access This is an Open Access article distributed in accordance with the Creative Commons Attribution Non Commercial (CC BY-NC 4.0) license, which permits others to distribute, remix, adapt, build upon this work non-commercially, and license their derivative works on different terms, provided the original work is properly cited and the use is non-commercial. See: http://creativecommons.org/ licenses/by-nc/4.0/

(c) Article author(s) (or their employer(s) unless otherwise stated in the text of the article) 2017. All rights reserved. No commercial use is permitted unless otherwise expressly granted.

\section{REFERENCES}

1. Kohn LT, Corrigan JM, Donaldson MS. Errors in health care: a leading cause of death and injury, 2000.

2. Langelaan M, De Bruijne M, Baines R, et al. Monitor Zorggerelateerde Schade 2011/2012: dossieronderzoek in Nederlandse ziekenhuizen, 2013.

3. Gawande AA, Zinner MJ, Studdert DM, et al. Analysis of errors reported by surgeons at three teaching hospitals. Surgery 2003;133:614-21.

4. Vincent C, Taylor-Adams S, Stanhope N. Framework for analysing risk and safety in clinical medicine. BMJ 1998;316:1154-7.

5. WHO. Guidelines for safe surgery: safe surgery saves lives: World Health Organization, 2009.

6. Fudickar A, Hörle K, Wiltfang J, et al. The effect of the WHO Surgical Safety Checklist on complication rate and communication. Dtsch Arztebl Int 2012;109:695-701.

7. Weiser TG, Haynes AB, Dziekan G, et al. Effect of a 19-item surgical safety checklist during urgent operations in a global patient population. Ann Surg 2010;251:976-80.

8. Treadwell JR, Lucas S, Tsou AY. Surgical checklists: a systematic review of impacts and implementation. BMJ Qual Saf 2014;23:299-318.

9. Pugel AE, Simianu VV, Flum DR, et al. Use of the surgical safety checklist to improve communication and reduce complications. $J$ Infect Public Health 2015;8:219-25.

10. Neuhaus C, Spies A, Wilk H, et al. "Attention Everyone, Time Out!": safety attitudes and checklist practices in anesthesiology in Germany. A cross-sectional study. J Patient Saf 2017.

11. Fourcade A, Blache JL, Grenier C, et al. Barriers to staff adoption of a surgical safety checklist. BMJ Qual Saf 2012;21:191-7.

12. Levy SM, Senter CE, Hawkins RB, et al. Implementing a surgical checklist: more than checking a box. Surgery 2012;152:331-6.

13. Joint Cormission International (JCl). 2017. Exit Report. Radboud University Medical Center Nijmegen, Netherlands: Internafional Health Care Organization (IHCO). Identification Number: 60004145.

14. Russ S, Rout S, Sevdalis N, et al. Do safety checklists improve teamwork and communication in the operating room? A systematic review. Ann Surg 2013;258:856-71.

15. Cramm JM, Strating MM, Nieboer AP. The role of team climate in improving the quality of chronic care delivery: a longitudinal study among professionals working with chronically ill adolescents in transitional care programmes. BMJ Open 2014;4:e005369.

16. Campbell SM, Hann M, Hacker J, et al. Identifying predictors of high quality care in English general practice: observational study. BMJ 2001;323:784.

17. Papaspyros SC, Javangula KC, Adluri RK, et al. Briefing and debriefing in the cardiac operating room. Analysis of impact on theatre team attitude and patient safety. Interact Cardiovasc Thorac Surg 2010;10:43-7.

18. Ahmed K, Khan N, Anderson D, et al. Introducing the productive operating theatre programme in urology theatre suites. Urol Int 2013;90:417-21.

19. Awad SS, Fagan SP, Bellows $C$, et al. Bridging the communication gap in the operating room with medical team training. Am J Surg 2005;190:770-4.

20. Ouwens M, Hulscher M, Akkermans R, et al. The Team Climate Inventory: application in hospital teams and methodological considerations. Qual Saf Health Care 2008;17:275-80.

21. Anderson NR, West MA. Measuring climate for work group innovation: development and validation of the team climate inventory. J Organ Behav 1998;19:235-58.

22. Hsieh HF, Shannon SE. Three approaches to qualitative content analysis. Qual Health Res 2005;15:1277-88.

23. Ali M, Osborne A, Bethune R, et al. Preoperative surgical briefings do not delay operating room start times and are popular with surgical team members. J Patient Saf 2011;7:138-42.

24. NHS Institute for Innovation and Improvement. Evaluation of The Productive Operating Theatre programme: NHS Institute for Innovation and Improvement, 2013. Available from. http:// harmfreecare.org/wp-content/files_mf/Evaluation-of-The-Productive- 
Operating-Theatre-programme-FINAL.pdf (accessed August, 23 2017).

25. Bartz-Kurycki MA, Anderson KT, Abraham JE, et al. Debriefing: the forgotten phase of the surgical safety checklist. J Surg Res 2017;213:222-7.

26. Wolfe H, Zebuhr C, Topjian AA, et al. Interdisciplinary ICU cardiac arrest debriefing improves survival outcomes*. Crit Care Med 2014;42:1688-95.

27. Lemson J, Haerkens M. Never waste an opportunity to debrief* ${ }^{\star}$. Crit Care Med 2014;42:1740-1.
28. Dykema J, Jones NR, Piché T, et al. Surveying clinicians by web: current issues in design and administration. Eval Health Prof 2013;36:352-81.

29. Dobrow MJ, Orchard MC, Golden B, et al. Response audit of an Internet survey of health care providers and administrators: implications for determination of response rates. J Med Internet Res 2008;10:e30.

30. Sexton JB, Helmreich RL, Neilands TB, et al. The Safety Attitudes Questionnaire: psychometric properties, benchmarking data, and emerging research. BMC Health Serv Res 2006;6:44. 